\title{
Endothelial Regulation of Vascular Tone and Growth
}

\author{
Thomas F. Lüscher and Felix C. Tanner
}

The endothelium regulates vascular tone by releasing factors involved in relaxation and contraction, in coagulation and thrombus formation, and in growth inhibition and stimulation. Endothelium-dependent relaxations are elicited by transmitters, hormones, platelet substances, and the coagulation system, and by physical stimuli such as the shear stress from circulating blood. They are mediated by the endothelium-derived relaxing factor, recently identified as nitric oxide, which causes vasodilation and platelet deactivation. Other proposed endothelium-derived relaxing factors include a hyperpolarizing factor, lipooxygenase products, and the cytochrome P450 pathway. Endothelium-derived contracting factors are produced by the cyclooxygenase pathway and by endothelial cells, which produce the peptide endothelin-1, a potent vasoconstrictor that under normal conditions circulates at low levels. The endothelium produces both growth inhibitors-normally dominant-and growth stimuli. Denuded or dysfunctional endothelium leads to a proliferative response and intimal hyperplasia in the vessel wall; moreover, platelets adhere to the site and release potent growth factors. Endothelial dysfunction has numerous causes: Aging is associated with increased formation of contracting factor and decreased relaxing factor; denudation, such as by coronary angioplasty, impairs the capacities of regenerated endothelial cells; oxidized low-density lipoproteins and hypercholesterolemia interfere with nitric oxide production; hypertension morphologically and functionally alters the endothelium; and atherosclerosis markedly attenuates some endothelium-dependent relaxations. For patients with coronary bypass grafts, differences in endotheliumderived vasoactive factors between the internal mammary artery and the saphenous vein may be important determinants of graft function, with the mammary artery having more pronounced relaxations than the saphenous vein and thus a higher patency rate. Am J Hypertens 1993;6:283S-293S

KEY WORDS: Endothelial regulation, endothelial dysfunction, vascular tone, endothelium-derived relaxing factors, endothelium-derived contracting factors, nitric oxide.
$\mathrm{T}$ he endothelium takes part in the regulation of vascular tone $\mathrm{e}^{1}$ by releasing relaxing and contracting factors both under basal conditions and when activated by neurotransmitters, hormones, autacoids, or physical stimuli. In addition, endothelial cells release factors involved in coagulation and thrombus formation and in growth inhibition and stimulation.

Owing to its strategic anatomic position, the endothelium is a target organ for hypertension, diabetes, and hyperlipidemia. ${ }^{1}$ Alterations in endothelial function may contribute to the pathogenesis as well as to the pro- gression and complications of hypertension and its sequelae such as atherosclerotic vascular disease.

From the Department of Medicine, Division of Clinical Pharmacology, and the Department of Research, Laboratory of Vascular Research, University Hospital, Basel, Switzerland.

Original research was supported by the Swiss National Research Foundation Grant 32-254.68.88, SCORE Grant 3231-025.150, the Swiss Cardiology Foundation, the Helmut Horten Foundation, and the Swiss Foundation for Nutrition Research.

Address correspondence and reprint requests to Thomas $\mathrm{F}$. Lüscher, MD, Division of Cardiology, University Hospital, 3010 Bern, Switzerland. 


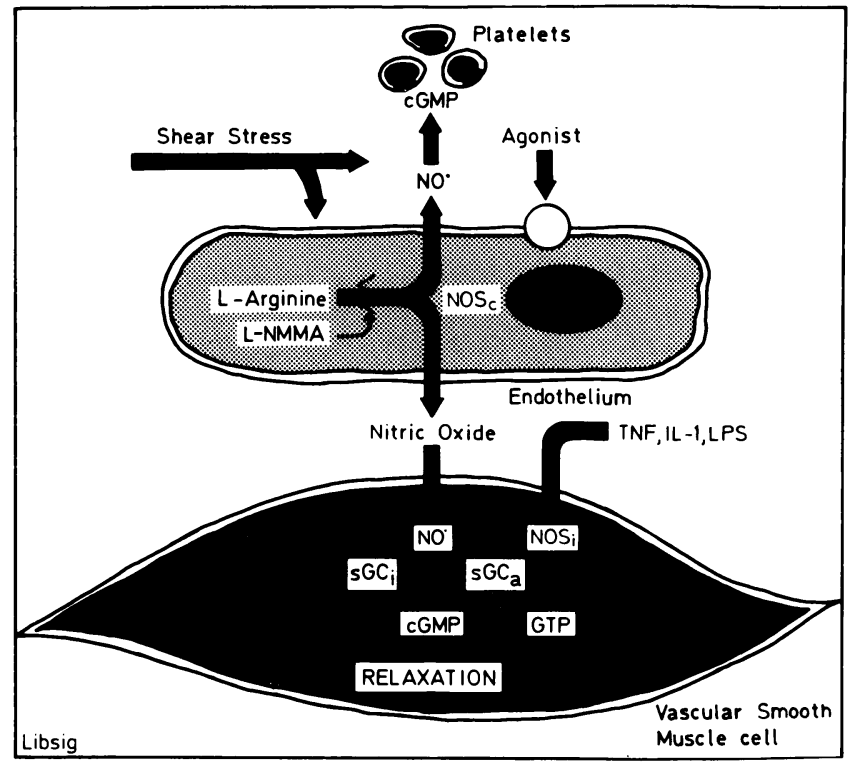

FIGURE 1. The L-Arginine pathway in the blood vessel wall: Endothelial cells form nitric oxide (NO) from L-arginine by the activity of the constitutive nitric oxide synthase (NOs $s_{c}$, which can be inhibited by analogs of the amino acid such as $L-\mathrm{N}^{G}$-monomethyl arginine (L-NMMA). Nitric oxide activates soluble guanylyl cyclase (sGC) in vascular smooth muscle and platelets and causes increases in cyclic $3^{\prime}, 5^{\prime}$-guanosine monophosphate (cGMP), which mediates relaxation and platelet inhibition, respectively. Shear stress and receptor-operated agonists (not shown) stimulate the release of nitric oxide. In addition, vascular smooth muscle cells can form nitric oxide by the activity of an inducible (by tumor necrosis factor, interleukin 1, and lipopolysaccharide) form of nitric oxide synthase $\left(\operatorname{NOS}_{i}\right)$.

\section{ENDOTHELIUM-DEPENDENT REGULATION OF VASCULAR TONE}

Relaxing Factors Endothelium-dependent relaxations occur both in vitro and in vivo ${ }^{2-4}$; transmitters, hormones, substances derived from platelets, and the coagulation system can cause these responses. ${ }^{1}$ Furthermore, physical stimuli, such as shear stress (exerted by the circulating blood), elicit endothelium-dependent vasodilation. 5

Endothelium-derived Nitric Oxide The relaxations are mediated by a diffusible substance with a half-life of a few seconds, ${ }^{6}$ the so-called endothelium-derived relaxing factor (EDRF), ${ }^{2}$ which has recently been identified as nitric oxide. ${ }^{7}$ Endothelium-derived nitric oxide (EDNO) has the same chemical characteristics as EDRF and is liberated in amounts sufficient to account for the vascular action of EDRF.7 Possibly, EDNO is not released as a free radical, but rather as a nitrosylated compound, for instance, $S$-nitrosocysteine. ${ }^{8}$

EDNO is formed from L-arginine by oxidation of the guanidine-nitrogen terminal of L-arginine (Figure 1). ${ }^{9}$ Nitric oxide synthase has been cloned recently ${ }^{10}$; it is primarily a cytosolic enzyme requiring calmodulin, calcium, and NADPH, and has similarities to cytochrome P450 enzymes. ${ }^{10,11}$ Several isoforms of the enzyme occur not only in endothelial cells, but also in platelets, macrophages, vascular smooth muscle cells, and in the brain. ${ }^{12-15}$ Endothelium-dependent relaxations to serotonin are inhibited by analogs of L-arginine such as $\mathrm{L}-\mathrm{N}^{\mathrm{G}}$-monomethyl arginine (L-NMMA) and are restored by L-arginine, but not by D-argin-
With Endothelium

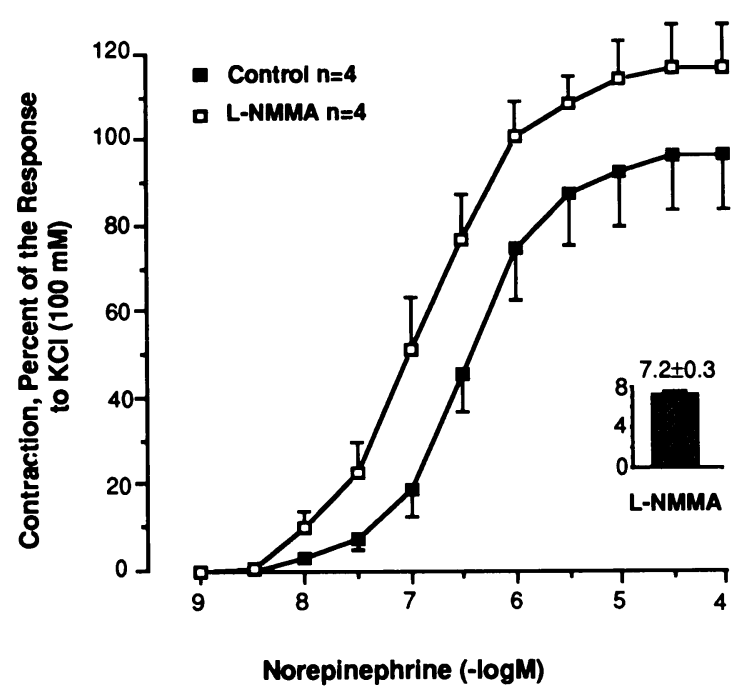

Without Endothelium

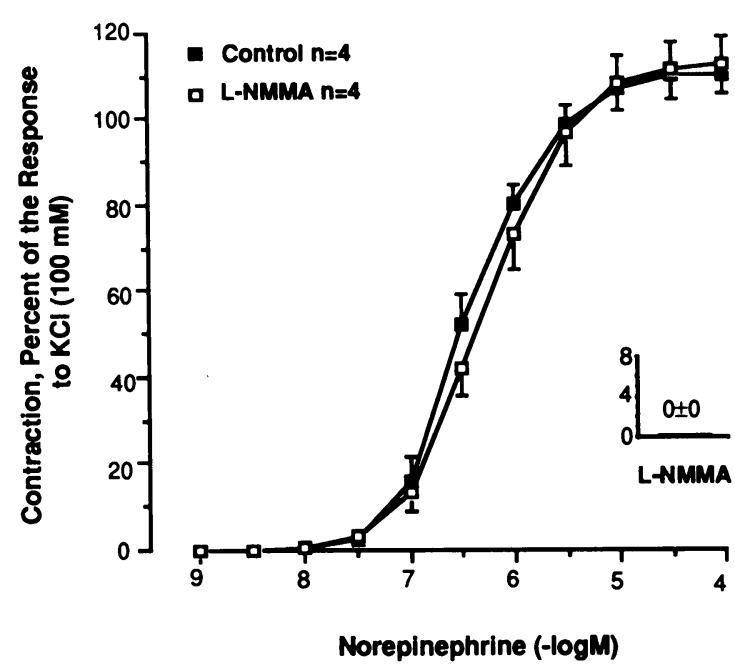

FIGURE 2. Endothelium-dependent effects to the inhibitor of nitric oxide formation $L-\mathrm{N}^{G}$-monomethyl arginine (L-NMMA) in the human internal mammary artery. In the preparation with endothelium, L-NMMA causes concentration-dependent contractions and augments those to norepinephrine. In contrast, in the preparation without endothelium, L-NMMA has no effect. From Yang et al ${ }^{3}$ with permission. 


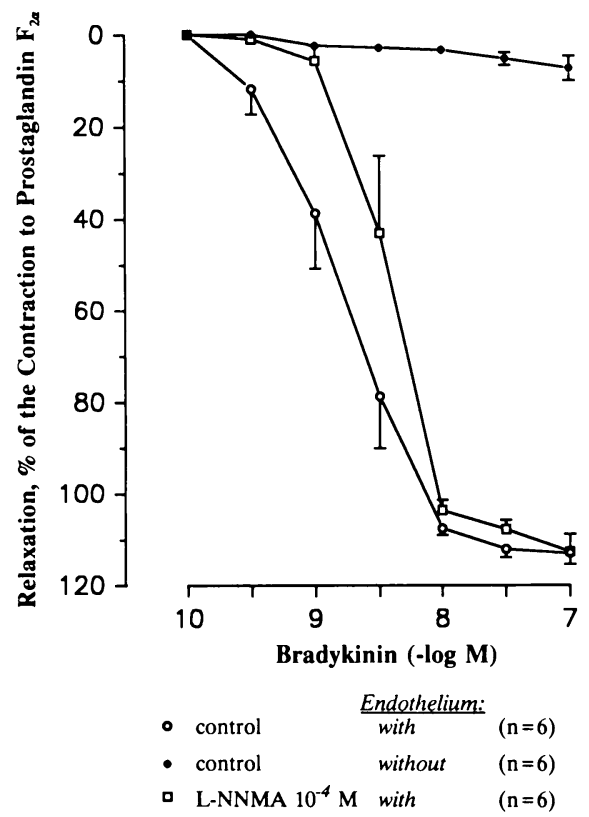

ine. ${ }^{3,16}$ In quiescent arteries, L-NMMA causes endothelium-dependent contractions (Figure 2). ${ }^{3}$ When infused in rabbits, it causes long-lasting increases in blood pressure that are reversible by L-arginine, ${ }^{17}$ demonstrating that the vasculature is in a constant state of vasodilation as a result of the continuous release of nitric oxide from the endothelium.

Relaxations to EDNO are associated with an increase in cyclic 3',5'-guanosine monophosphate (cGMP) in vascular smooth muscle cells (Figure 1). ${ }^{18}$ Methylene blue, an inhibitor of soluble guanylyl cyclase, prevents the production of cGMP and inhibits endothelium-dependent relaxations, ${ }^{1,18}$ an indication that EDNO causes relaxations by stimulating the enzyme and, in turn, the formation of cGMP. Soluble guanylyl cyclase is also present in platelets and is activated by EDNO (Figure 1). ${ }^{19}$ Increased levels of cGMP in platelets are associated with reduced adhesion and aggregation. Because EDNO causes both vasodilatation and platelet deactivation, it represents an important antithrombotic feature of the endothelium.

Vascular Smooth Muscle-derived Nitric Oxide Although the media of the blood vessel wall normally does not produce nitric oxide, vascular smooth muscle cells (including those obtained from human vessels) can do so when stimulated by endotoxin and interleukin-1 (Figure 1). ${ }^{20-23}$ Thus, it appears that there are at least two enzymes for the production of nitric oxide: The constitutive endothelial enzyme is calcium dependent and produces picomoles of nitric oxide, whereas the inducible enzyme is calcium independent, produces nanomoles of nitric oxide, and is primarily expressed in smooth muscle cells and monocytes. Activation of the L-arginine pathway in smooth muscle cells by endotoxin, interleukin-1, and tumor necrosis factor may play a role in septic shock and explain why the cardiovascular system becomes resistant to catecholamines under these conditions. On the other hand, L-NMMA may provide a therapeutic tool as it can prevent nitric oxide formation in vascular smooth muscle cells stimulated with endotoxin; preliminary data indeed suggest that L-NMMA may be beneficial for patients in septic shock. ${ }^{24}$

Prostacyclin Prostacyclin increases cyclic 3', 5'-adenosine monophosphate (cAMP) in smooth muscle and in platelets and, thus, causes relaxation and inhibition of platelet aggregation. 1,25 However, the contribution of prostacyclin to endothelium-dependent relaxations is negligible. ${ }^{1}$ In human platelets, EDNO and prostacyclin synergistically inhibit aggregation. ${ }^{26}$

Other Endothelium-derived Relaxing Factors In the porcine coronary circulation, L-NMMA inhibits endothelium-dependent relaxations to serotonin, but not to bradykinin (Figure 3). ${ }^{16}$ As similar effects are obtained by other inhibitors of the action of EDNO, such as hemoglobin and methylene blue, endothelial cells appear to release another relaxing factor distinct from nitric oxide. Prostacyclin can be excluded, as it is a weak vasodilator of porcine coronary arteries, and indomethacin does not affect the response to bradykinin. Several candidates for these responses have been proposed, including a hyperpolarizing factor, products of lipooxygenase, or the cytochrome $\mathrm{P} 450$ pathway. ${ }^{1}$

Acetylcholine causes not only an endothelium-dependent relaxation, but also an endothelium-dependent hyperpolarization of vascular smooth muscle. ${ }^{27,28}$ Although the relaxation to the muscarinic agonist is sustained, the hyperpolarization is transient. An endo- 


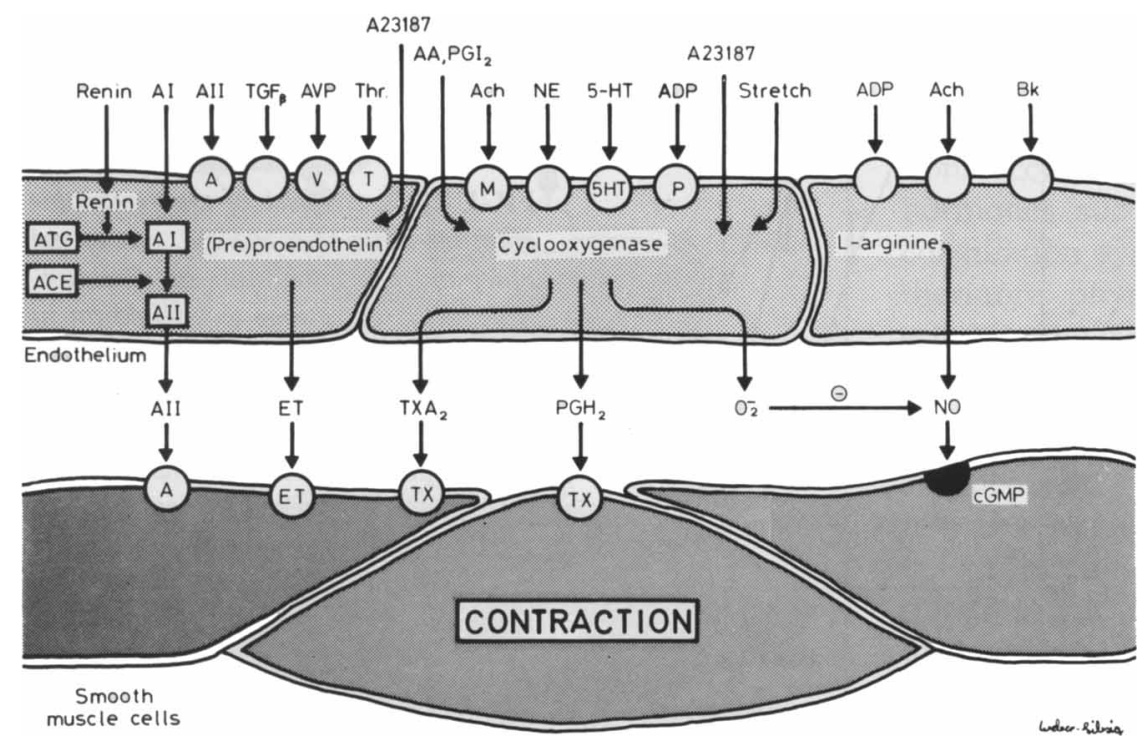

FIGURE 4. The endothelium is a source of different contracting factors. Products of cyclooxygenase, such as thromboxane $A_{2}$ (TX $\mathrm{A}_{2}$ ) and prostaglandin $\mathrm{H}_{2}\left(\mathrm{PGH}_{2}\right)$ have a direct contractile effect, while superoxide anions $\left(\mathrm{O}_{2}^{-}\right)$induce increases in tension by inactivating nitric oxide (NO). Endothelin (ET), as well as angiotensin II ( $A$ II), are also endothelium-derived contracting factors, as they are both produced by endothelial cells. thelium-dependent hyperpolarizing factor (EDHF) distinct from nitric oxide may be involved, although the latter was itself shown to have hyperpolarizing properties under certain conditions. ${ }^{27,29}$ The EDHF appears to activate ATP-sensitive potassium channels or sodium-potassium ATPase in smooth muscle, or both. 27,30 The hyperpolarization may contribute to endothelium-dependent relaxations or reduce the sensitivity of vascular smooth muscle to vasoconstrictor stimuli.

\section{Contracting Factors}

Cyclooxygenase-dependent Endothelium-derived Contracting Factor (EDCF) Exogenous arachidonic acid evokes endothelium-dependent contractions that can be prevented by indomethacin (an inhibitor of cyclooxygenase). ${ }^{31}$ In the human saphenous vein, acetylcholine and histamine evoke endothelium-dependent contractions; in the presence of indomethacin, however, these relaxations are unmasked. ${ }^{3}$ The products of cyclooxygenase mediating the contractions are thromboxane $\mathrm{A}_{2}$ in the case of acetylcholine and endoperoxides (prostaglandin $\mathrm{H}_{2}$ ) in that of histamine (Figure 4). ${ }^{3}$

The cyclooxygenase pathway is also a source of superoxide anions, which can mediate endothelium-dependent contractions either by the breakdown of nitric oxide or by direct effects on vascular smooth muscle (Figure 4). ${ }^{32}$ Thus, the cyclooxygenase pathway produces a variety of endothelium-derived contracting factors; their release appears to be more prominent in veins than in arteries. ${ }^{1}$

Endothelin Endothelial cells produce the 21amino-acid peptide endothelin (Figure 4). ${ }^{1,33}$ Among the three peptides-endothelin-1, endothelin-2, and endothelin-3-endothelial cells appear to produce endothelin-1 exclusively. ${ }^{1}$
Translation of messenger RNA generates preproendothelin, which is converted to big endothelin ${ }^{33}$; the formation of endothelin-1 by the endothelin-converting enzyme is then necessary for the development of full vascular activity. ${ }^{34}$ The expression of messenger RNA and the release of the peptide are stimulated by thrombin, transforming growth factor- $\beta$, interleukin- 1 , epinephrine, angiotensin II, arginine vasopressin, calcium ionophore, and phorbol ester (Figure 4). 1,33,35

Endothelin-1 is a potent vasoconstrictor both in vitro and in vivo. In the coronary circulation and the human forearm circulation, endothelin-1 causes vasodilation at lower concentrations and marked contractions at higher concentrations (Figure 5). ${ }^{36,37}$ In human arterial and venous coronary bypass vessels, it causes marked contractions. ${ }^{38}$

The circulating levels of endothelin-1 are very low, however, suggesting that little of the peptide is formed under physiological conditions. ${ }^{39}$ This may be related

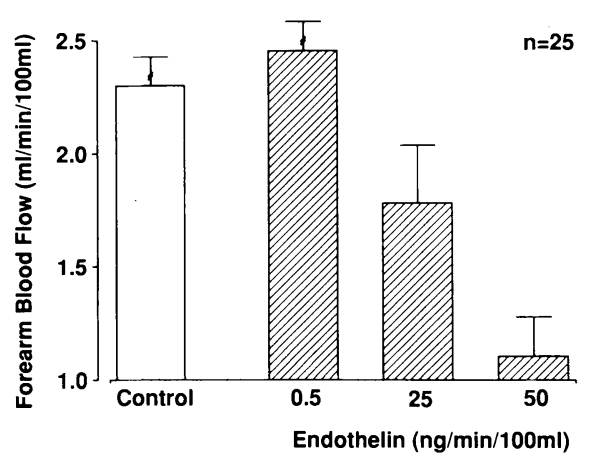

FIGURE 5. Effects of endothelin on blood flow in the human forearm circulation. Low concentrations of endothelin $(0.5 \mathrm{ng} / \mathrm{min} / 100$ $m L$ ) cause a slight increase, whereas higher concentrations of the peptide (25 and $50 \mathrm{ng} / \mathrm{min} / 100 \mathrm{~mL}$ ) induce a marked decrease of forearm blood flow. Modified from Kiowski et al ${ }^{37}$ with permission. 

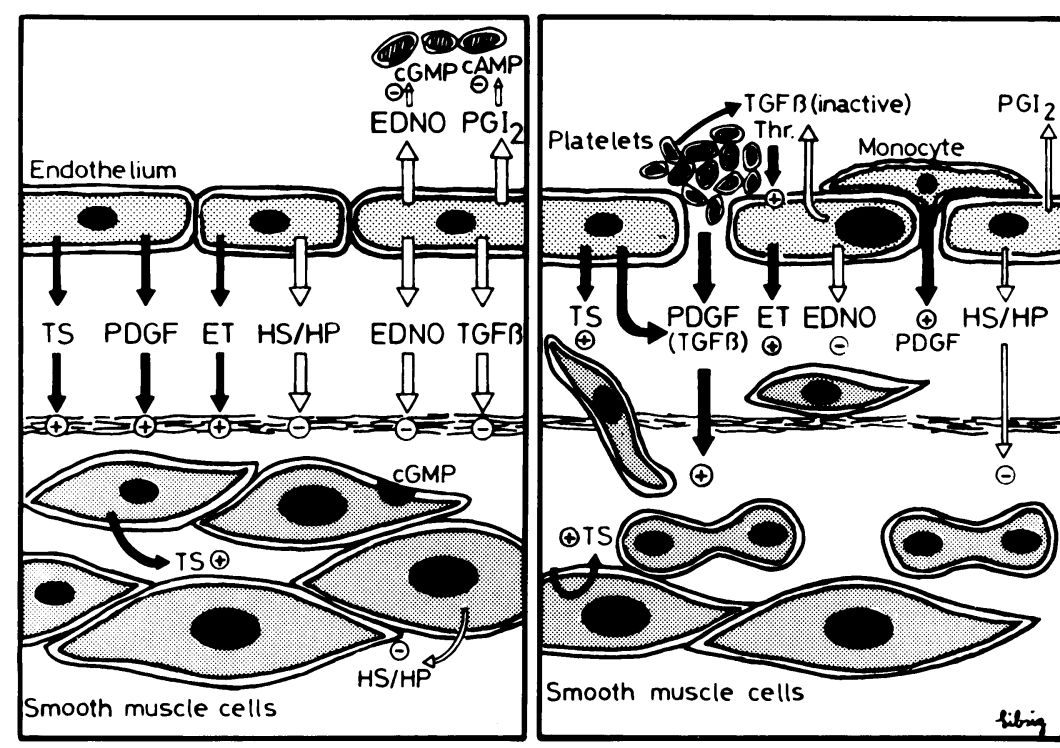

FIGURE 6. Endothelium and vascular growth. The endothelium produces growth inhibitors such asheparin (HP), heparin sulphates (HS), transforming growth factor beta (TGFB), and also nitric oxide (EDNO). On the other hand, it releases growth promotors, such as platelet-derived growth factor (PDGF), thrombospondin (TS), and possibly endothelin (ET). At sites of damaged endothelium the production of nitric oxide (EDNO) and prostacyclin $\left(\mathrm{PGI}_{2}\right)$ is diminished, favoring platelet adhesion and aggregation. PDGF is released by aggregating platelets and leads to proliferation as well as migration of vascular smooth muscle cells into the intima. The endothelium most probably takes part in these structural changes of the vascular wall, at least indirectly, by inhibiting platelet aggregation and with that the release of growth-stimulating factors. to the absence of stimuli or to the presence of potent inhibitory mechanisms, or to both, or it may be that the peptide is released preferentially toward vascular smooth muscle cells. ${ }^{35,40,41}$ Indeed, three inhibitory mechanisms regulating endothelin production have been delineated: 1) cGMP-dependent inhibition ${ }^{35}$; 2) cAMP-dependent inhibition ${ }^{42}$; and 3) an inhibitory factor produced by vascular smooth muscle cells. ${ }^{43}$ The cGMP-dependent mechanism can be activated by EDNO, nitroglycerine, 3-morpholino sydnominine $(\mathrm{SIN}-1),{ }^{44}$ and atrial natriuretic peptide (which activates particulate guanylyl cyclase). ${ }^{45}$ Thus, after inhibition of endothelial nitric oxide production, the thrombin-induced formation of endothelin is augmented $^{35}$; on the other hand, SIN-1 prevents the thrombin-induced endothelin release by a cGMP-dependent mechanism. ${ }^{44}$ Endothelin can also release nitric oxide and prostacyclin from endothelial cells in what may represent a negative feedback mechanism. ${ }^{40}$

The contraction to endothelin is not related to direct activation of voltage-operated calcium channels on vascular smooth muscle, as calcium antagonists do not prevent its effects in most blood vessels. ${ }^{40,46,47}$ However, the peptide activates indirectly those channels in the porcine coronary artery where calcium antagonists attenuate endothelin-induced vasoconstriction. ${ }^{48}$ In the human forearm circulation, endothelin-1 induces potent contractions, which can be prevented by nifedipine and verapamil hydrochloride, unmasking the vasodilator effects of the peptide. ${ }^{37}$ The vasodilator effects of endothelin are related to the endothelial production of prostacyclin, whereas nitric oxide may contribute to the relaxation effects. ${ }^{49}$ Although endothelin is a secretagogue for atrial natriuretic factor, its release is not involved in the vasodilator action of endothelin..$^{50}$

EDNO also interacts with endothelin at the level of vascular smooth muscle. Indeed, the contractions to the peptide are enhanced after endothelial removal, indicating that basal production of EDNO reduces the response to the peptide. ${ }^{38}$ Stimulation of the formation of EDNO by acetylcholine reverses endothelin-induced contractions in most blood vessels although this mechanism appears to be less potent in veins. ${ }^{38}$

\section{ENDOTHELIAL REGULATION OF VASCULAR GROWTH}

Removal of the endothelium is a procedure that invariably leads to a proliferative response in the blood vessel wall with intimal hyperplasia. ${ }^{51}$ Important growth inhibitors produced by the endothelium are heparin, heparin sulfates, transforming growth factor- $\beta$, and most likely nitric oxide. ${ }^{52,53}$ On the other hand, endothelial cells can also produce growth factors such as basic fibroblast growth factor, platelet-derived growth factor (PDGF), and possibly also endothelin (Figure 6). ${ }^{54,55}$ These factors contribute to proliferative responses, at least under certain conditions, whereas it has to be assumed that under normal conditions inhibitory stimuli prevail. At sites of endothelial denudation or dysfunction, platelets adhere and release potent growth factors such as PDGF. ${ }^{56}$ Hence, the platelet inhibitory effect ${ }^{19}$ of nitric oxide and prostacyclin also contribute indirectly to growth inhibition (Figure 6).

In vascular smooth muscle cells from saphenous vein coronary bypass grafts exposed to pulsatile stretch, the $\left[{ }^{3} \mathrm{H}\right]$ thymidine incorporation is enhanced after $24 \mathrm{~h}$ of stretch, whereas the cell number is increased after 6 days. In contrast, both $\left[{ }^{3} \mathrm{H}\right]$ thymidine incorporation and cell number remain constant in vascular smooth muscle cells from internal mammary arteries (Figure 7). ${ }^{57}$ Thus, the stimulation by pulsatile stretch of vascular smooth muscle cell proliferation in saphenous vein, but not in internal mammary artery, may contribute to the higher occlusion rate of venous 

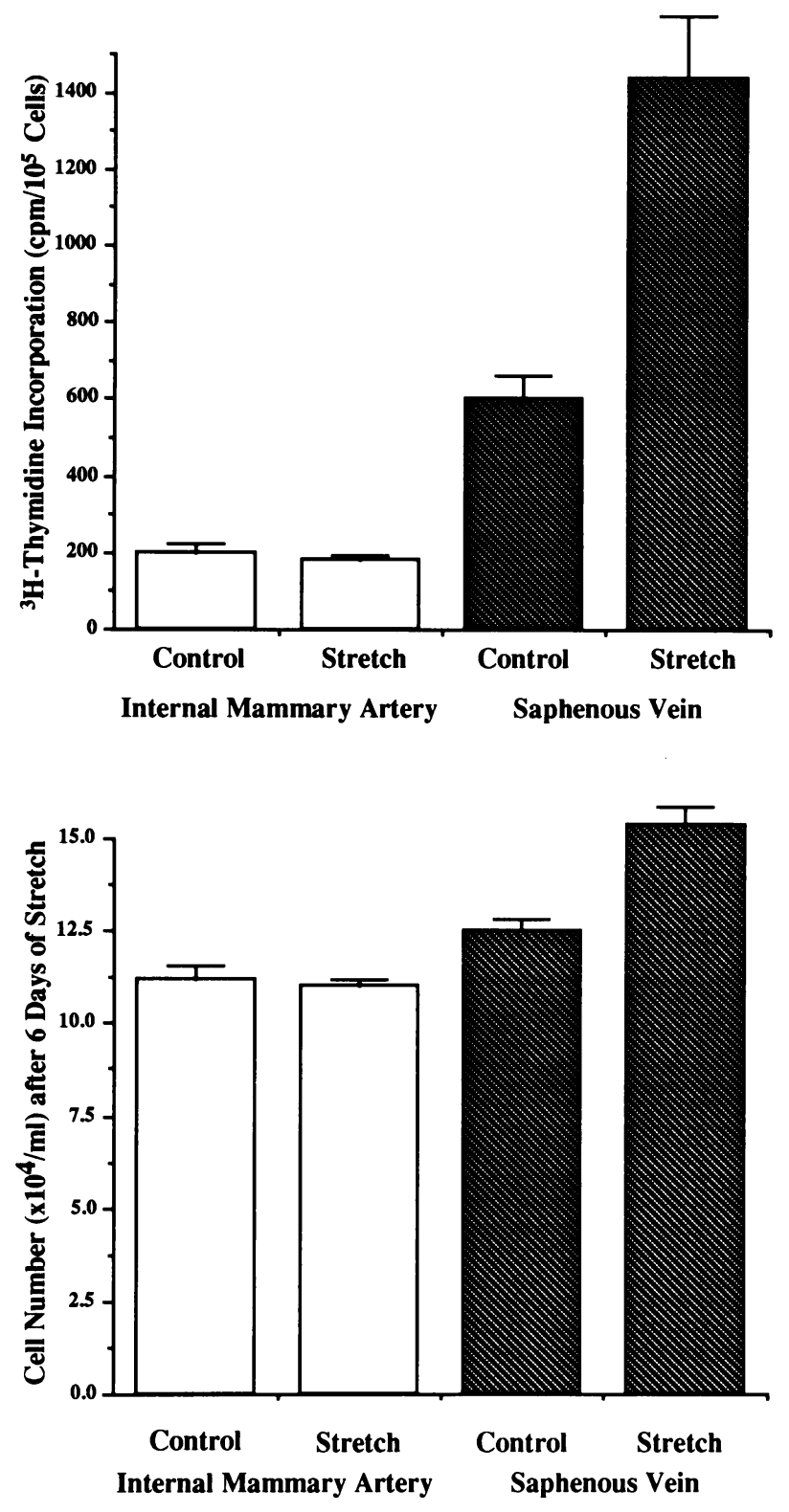

FIGURE 7. Proliferative responses to pulsatile stretch (60 cycles/min) of human vascular smooth muscle cells from internal mammary artery and saphenous vein. After $24 h$ of pulsatile stretch the $\left[{ }^{3} \mathrm{H}\right]$ thymidine incorporation (top) was increased in saphenous vein but not in mammary artery. After 6 days of stretch (lower) the cell number was increased in the vein but not in the artery. From Preded et al ${ }^{57}$ with permission.

coronary bypass grafts. As shear forces stimulate the release of nitric oxide and prostacyclin from the endothelium, it is possible that the growth responses of vascular smooth muscle cells are modulated by or inhibited in the presence of endothelial cells.

\section{ENDOTHELIAL DYSFUNCTION}

Because of its strategic anatomic position between the circulating blood and vascular smooth muscle, the en- dothelium is a primary target organ for cardiovascular risk factors and mechanical forces, such as pressure and shear stress, particularly at branching sites where blood flow is nonlaminar. ${ }^{1}$

Aging Aging is one of the most important determinants of vascular disease. In the rat, aging is associated with an increased formation of the EDCF (prostaglandin $\mathrm{H}_{2}$ ), 58 as well as a mild decrease in the release of EDRF. ${ }^{59}$ In contrast, the responsiveness of vascular smooth muscle to nitric-oxide-forming compounds does not change under these conditions. ${ }^{58}$ In the human coronary microcirculation, the increase in coronary flow induced by intraarterial infusions of acetylcholine declines with aging. ${ }^{60}$

Endothelial Regeneration After mechanical denudation of the porcine coronary artery, the capacity of regenerated endothelial cells to release EDNO in response to platelet-derived serotonin is impaired because of a defect of the $G_{i}$ protein linked to the endothelial $5 \mathrm{HT}_{1}$-serotonergic receptor. ${ }^{61}$ These functional alterations occurring during regeneration may contribute to the age-dependent impairments of endothelial function in the coronary circulation and may also play a role after percutaneous transluminal coronary angioplasty. Dysfunction of the endothelium, particularly in response to platelet-derived products, may increase platelet adhesion, thereby providing high local concentrations of platelet-derived growth factor and contributing to the proliferative response at sites of endothelial dysfunction.

Lipoproteins and Hypercholesterolemia Morphologically, the endothelium remains intact during the early stages of atherogenesis; functionally, however, pronounced alterations occur. ${ }^{1}$ Particularly, oxidized low-density lipoprotein (OX-LDL) is present in human atherosclerotic lesions. ${ }^{62}$ In the porcine coronary artery, OX-LDL inhibits endothelium-dependent relaxations to platelets, serotonin, and thrombin. ${ }^{63}$ In contrast, relaxations to the nitric oxide donor SIN-1 are well maintained, excluding a reduced responsiveness of vascular smooth muscle to EDNO. The inhibition is specific for OX-LDL, as it is not induced by comparable concentrations of native LDL. In the rabbit aorta the effect of OX-LDL is mimicked by lysolecithin (a characteristic component of OX-LDL). ${ }^{64,65}$

OX-LDL appears to activate an endothelial receptor distinct from the LDL receptor, such as the scavenger receptor (Figure 8) 63,65 ; indeed, dextran sulfate, a competitive antagonist of modified LDL at this receptor, prevents the endothelial effects of OX-LDL. ${ }^{63}$ Because endothelium-dependent relaxations to serotonin, but not to bradykinin, are inhibited by the lipoproteins, they specifically interfere with endothelial production of nitric oxide, whereas that of other EDRFs does not 


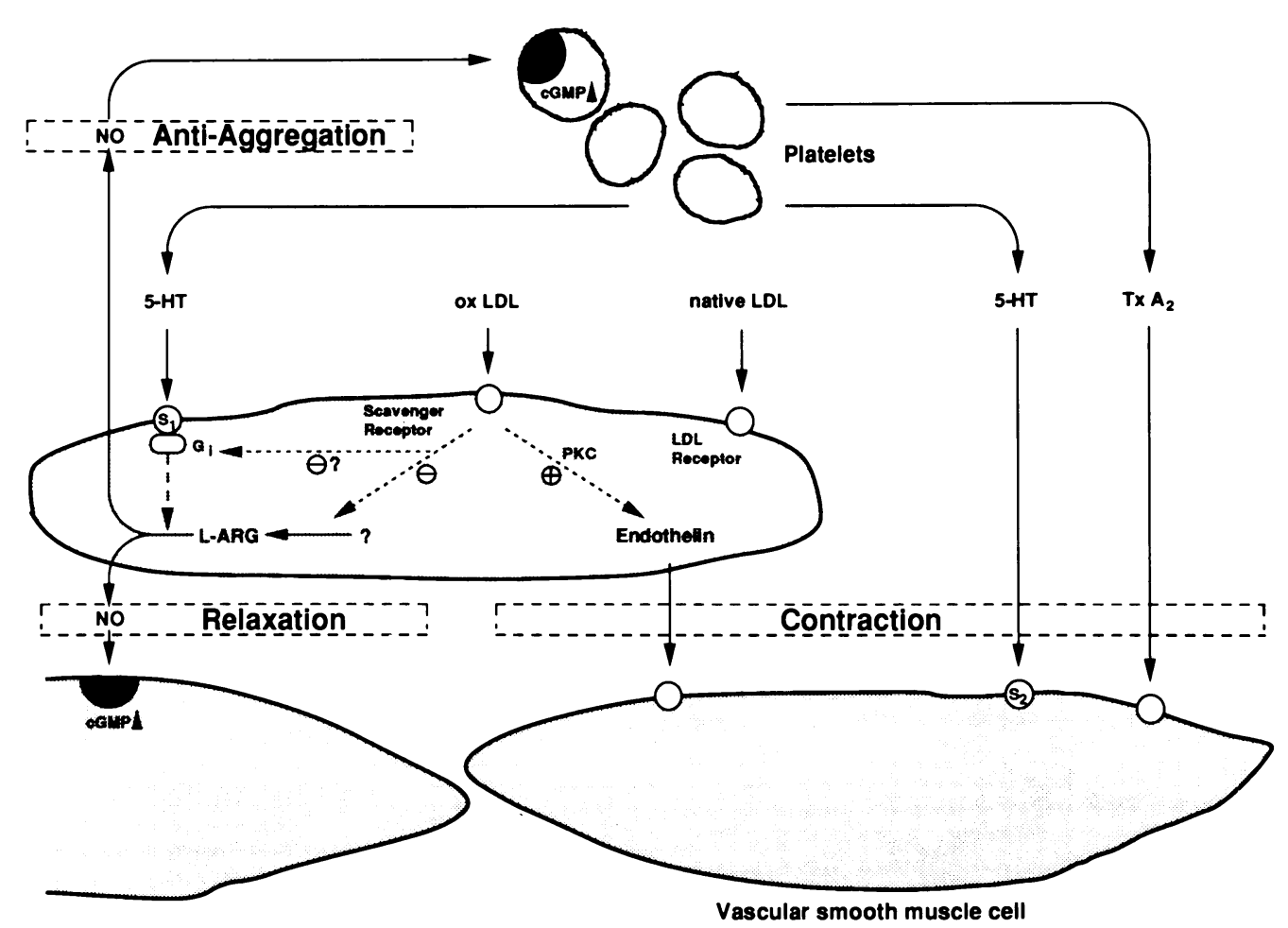

FIGURE 8. Schematic representation of the effects of oxidized low-density lipoprotein $(O x-L D L)$ on the endothelial L-arginine pathway in the coronary circulation: $O x$-LDL activates the endothelial scavenger receptor and interferes with the intracellular availability of $L$-arginine (L-ARG). This reduces the efficacy of the receptor-operated activation of the L-arginine pathway by serotonin (5-HT) and other mediators, and thus favors vascular contraction and platelet aggregation. Modified from Tanner et al ${ }^{65}$ with permission.

seem to be affected. Nitric oxide synthetase remains unaffected, however, as L-arginine evokes a full relaxation in vessels treated with OX-LDL. Because pretreatment with L-arginine restores the response to serotonin in vessels treated with OX-LDL, it may be that OX-LDL interacts with the intracellular availability of L-arginine (Figure 8). 63,65

This mechanism may also occur in vivo, as a similar inhibition of endothelium-dependent relaxation to serotonin and to bradykinin occurs in hypercholesterolemic pigs as in coronary arteries exposed to OX-LDL. ${ }^{66}$ In humans with hypercholesterolemia, L-arginine infusion augments the blunted increase in coronary blood flow in response to acetylcholine ${ }^{67}$; in contrast, the loss of endothelium-dependent vasodilation to acetylcholine in epicardial coronary arteries is unaffected by the amino acid, possibly because of the presence of fully developed atherosclerosis.

In addition to their effect on the L-arginine pathway, both native and OX-LDL inactivate nitric oxide. ${ }^{68} \mathrm{OX}$ LDL not only inhibits endothelium-dependent relaxation, but also causes endothelium-dependent contraction. ${ }^{69}$ In the rabbit femoral artery, OX-LDL potentiates contractions to potassium chloride as well as to receptor-operated vasoconstrictors. ${ }^{70}$

OX-LDL also induces the expression of messenger RNA for endothelin in cultured aortic endothelial cells as well as the release of the peptide from the intact porcine aorta (Figure 8). ${ }^{71}$ In this context it is of interest that threshold and low concentrations of endothelin, which by themselves evoke no appreciable vascular effect, potentiate contractions induced by serotonin in the human coronary artery and by norepinephrine and serotonin in the human internal mammary artery. ${ }^{72}$ Thus, OX-LDL inhibits endothelium-dependent relaxations and promotes endothelium-dependent as well as endothelium-independent contractions; the consequences are alterations in vascular tone leading to vasospasm and thrombus formation, both common events in patients with coronary artery disease.

Hypertension Hypertension is associated with morphological and functional alterations of the endothelium. ${ }^{1}$ In hypertensive blood vessels, endothelial cells have an increased volume, bulging into the lumen, and fibrin and cell deposition is increased in the subintimal space. Furthermore, the interaction of platelets and monocytes with the endothelium is increased in hypertensive vessels compared with normotensive controls.

Endothelium-dependent relaxations to acetylcholine are reduced in the aortic, cerebral, and peripheral microcirculations of hypertensive rats. ${ }^{73,74}$ Similarly, the vasodilator effects of acetylcholine in the 


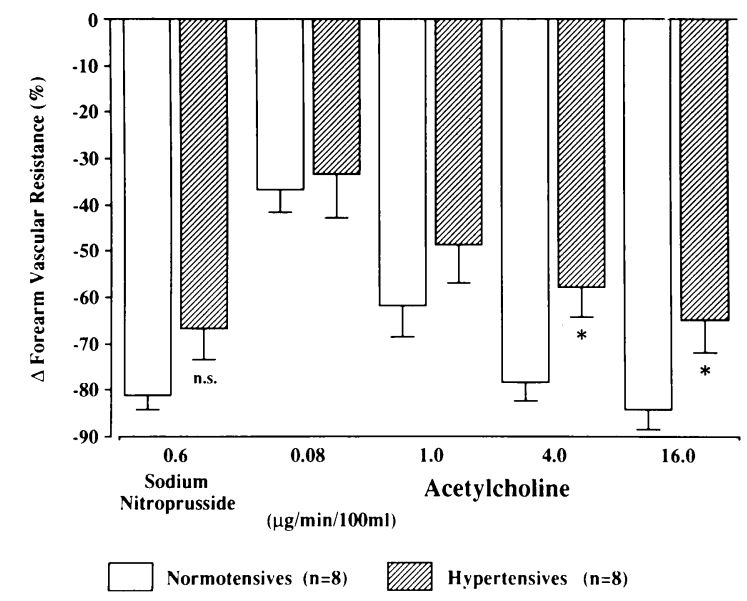

FIGURE 9. Effects of intraarterially infused acetylcholine on forearm vascular resistance in normotensive subjects (open bars) and patients with essential hypertension (hatched bars). Note the reduced effects of acetylcholine in the hypertensive patients. n.s., not significant; ${ }^{*}, \mathrm{P}<.05$ From Linder et al ${ }^{4}$ with permission.

human forearm of hypertensive subjects is blunted (Figure 9). ${ }^{4}$ In the spontaneously hypertensive rat, the reduced response to acetylcholine is related to the production of EDCF (ie, prostaglandin $\mathrm{H}_{2}$ ), whereas in most other forms of experimentally induced hypertension a reduced formation of EDNO predominates. ${ }^{74}$ In the mesenteric microcirculation, intraluminal (but not extraluminal) activation of the endothelium is dysfunctional, indicating a predominant alteration of that surface of the endothelium most exposed to high blood pressure. ${ }^{74}$

In contrast, the coronary circulation-at least as judged from work with the spontaneously hypertensive rat model-appears less prone to hypertensive endothelial dysfunction. Indeed, in epicardial coronary arteries of these rats, aging and hypertension only minimally reduce the response to acetylcholine, ${ }^{75}$ suggesting that in the absence of hyperlipidemia, hypertension exerts only a mild effect on the coronary endothelium.

Atherosclerosis In porcine coronary arteries, endothelium-dependent relaxations are severely impaired to serotonin and also reduced to bradykinin by established atherosclerosis. ${ }^{66}$ Endothelium-independent relaxations to nitrovasodilators remain preserved, however, except in severely atherosclerotic arteries. ${ }^{1}$

In human coronary arteries, atherosclerosis attenuates endothelium-dependent relaxations to substance $\mathrm{P}$, bradykinin, aggregating platelets, and calcium ionophore, ${ }^{76,77}$ and in vivo acetylcholine and serotonin cause paradoxical vasoconstriction. ${ }^{78,79}$

The nature of the mechanism responsible for the marked impairment or loss of endothelium-dependent relaxations in atherosclerosis is controversial. The re- lease of EDRF clearly is reduced in porcine coronary arteries with hypercholesterolemia and atherosclerosis. ${ }^{66}$ Direct measurements of nitric oxide in the rabbit aorta, however, suggest an increased formation of nitric oxide with a concomitant massive breakdown of the endogenous nitrovasodilator. ${ }^{80}$ The latter observation suggests that atherosclerosis is associated with increased formation of superoxide radicals and other products inactivating nitric oxide or with decreased activity of superoxide dismutase in the blood vessel wall, or both. It is conceivable that during the more developed stages of atherosclerosis, the marked invasion of monocytes and other blood cells induces nitric oxide synthase in the subintimal space and vascular smooth muscle cells. However, it is not known whether alterations similar to those in the rabbit aorta occur in human coronary arteries.

Coronary Bypass Grafts In patients with coronary artery disease, surgical therapy involves implantation of an arterial or venous bypass graft using the internal mammary, gastroepiploic artery, or saphenous vein. The mammary artery has a remarkably higher patency rate than the saphenous vein. ${ }^{81}$ Endothelium-derived vasoactive factors may be important to graft function as they determine the antithrombotic properties and the regulation of blood flow. In addition, these factors may have antiproliferative and proliferative properties determining the late changes occurring in coronary bypass grafts.

The mammary artery exhibits much more pronounced endothelium-dependent relaxations than does the saphenous vein, because the release of EDNO by receptor-operated agonists and, in particular, by aggregating platelets is more efficient in the artery than in the vein. 82,83 Particularly, the release of EDNO in response to platelet-derived adenosine diphosphate is an important antithrombotic property. The gastroepiploic artery releases amounts of EDNO comparable with those released by the mammary artery, but exhibits more pronounced contractions. ${ }^{84}$ These differences in endothelial and vascular smooth muscle functions of bypass graft vessels (Figures 6,7) may play an important role in graft function and patency, and, hence, in the survival of patients undergoing coronary bypass surgery.

\section{ACKNOWLEDGMENTS}

The authors thank Amanda de Sola Pinto and Bernadette Weber-Libsig for their help in preparing the manuscript.

\section{REFERENCES}

1. Lüscher TF, Vanhoutte PM: The Endothelium-Modulator of Cardiovascular Function. Boca Raton, CRC Press, 1990, pp 1-215. 
2. Furchgott RF, Zawadzki JV: The obligatory role of endothelial cells in the relaxation of arterial smooth muscle by acetylcholine. Nature 1980;299:373-376.

3. Yang Z, von Segesser L, Bauer E, et al: Different activation of endothelial L-arginine and cyclooxygenase pathway in human internal mammary artery and saphenous vein. Circ Res 1991;68:52-60.

4. Linder L, Kiowski W, Bühler FR, Lüscher TF: Indirect evidence for release of endothelium-derived relaxing factor in human forearm circulation in vivo: blunted response in essential hypertension. Circulation 1990;81:1762-1767.

5. Rubanyi GM, Romero JC, Vanhoutte PM: Flow-induced release of endothelium-derived relaxing factor. Am J Physiol 1986;250:H1145-1149.

6. Rubanyi GM, Vanhoutte PM: Superoxide anions and hyperoxia inactivate endothelium-derived relaxing factor. Am J Physiol 1986;250:H822-827.

7. Palmer RMI, Ferrige AG, Moncada S: Nitric oxide release accounts for the biological activity of endothelium-derived relaxing factor. Nature 1987;327:524-526.

8. Myers PR, Minor RL Jr, Guerra R Jr, et al: Vasorelaxant properties of the endothelium-derived relaxing factor more closely resemble S-nitrosocysteine than nitric oxide. Nature 1990;345:161-163.

9. Palmer RMJ, Ashton DS, Moncada S: Vascular endothelial cells synthesize nitric oxide from L-arginine. $\mathrm{Na}$ ture 1988;333:664-666.

10. Bredt DS, Hwang PM, Glatt CE, et al: Cloned and expressed nitric oxide synthase structurally resembles cytochrome P-450 reductase. Nature 1991;351:714-718.

11. Bredt DS, Snyder SH: Isolation of nitric oxide synthetase, a calmodulin-requiring enzyme. Proc Natl Acad Sci USA 1990;87:682-685.

12. Radomski MW, Palmer RMJ, Moncada S: An L-arginine/nitric oxide pathway present in human platelets regulates aggregation. Proc Natl Acad Sci USA 1990;87:5193-5197.

13. Hibbs JB, Traintor RR, Vavrin Z, Rachlin EM: Nitric oxide: a cytotoxic activated macrophage molecule. Biochem Biophys Res Comm 1988;157:87-94.

14. Wood KS, Buga GM, Byrns RE, Ignarro LJ: Vascular smooth muscle-derived relaxing factor (MDRF) and its close similarity to nitric oxide. Biochem Biophys Res Commun 1990;170:80-88.

15. Knowles RG, Palacios M, Palmer RMJ, Moncada S: Formation of nitric oxide from L-arginine in the central nervous system: a transduction mechanism for stimulation of the soluble guanylate cyclase. Proc Natl Acad Sci USA 1989;86:1-4.

16. Richard V, Tanner FC, Tschudi M, Lüscher TF: Different activation of L-arginine pathway by bradykinin, serotonin, and clonidine in coronary arteries. Am J Physiol 1990;259:H1433-1439.

17. Rees DD, Palmer RMJ, Moncada S: Role of endothelium-derived nitric oxide in the regulation of blood pressure. Proc Natl Acad Sci USA 1989;86:3375-3378.

18. Rapoport RM, Murad F: Agonist-induced endothelium-dependent relaxation in rat thoracic aorta may be mediated through cGMP. Circ Res 1983;52:352-357.
19. Busse R, Lückhoff A, Bassenge E: Endothelium-derived relaxant factor inhibits platelet activation. NaunynSchmiedeberg's Arch Pharmacol 1987;336:566-571.

20. Bernhardt J, Tschudi MR, Dohi Y, et al: Release of nitric oxide from human vascular smooth muscle cells. Biochem Biophys Res Commun 1991;180:907-912.

21. Fleming I, Gray GA, Julou-Schaeffer G, et al: Incubation with endotoxin activates the L-arginine pathway in vascular tissue. Biochem Biophys Res Commun 1990;171:562-568.

22. Rees DD, Cellek S, Palmer RMJ, Moncada S: Dexamethasone prevents the induction by endotoxin of a nitric oxide synthase and the associated effects on vascular tone: an insight into endotoxin shock. Biochem Biophys Res Commun 1990;173:541-547

23. Schini VB, Junquero DC, Scott-Burden T, Vanhoutte PM: Interleukin-1 beta induces the production of an Larginine-derived relaxing factor from cultured smooth muscle cells from rat aorta. Biochem Biophys Res Commun 1991;176:114-121.

24. Petros A, Bennett D, Vallance P: Effect of nitric oxide synthase inhibitors on hypotension in patients with septic shock. Lancet 1991;338:1557-1558.

25. Moncada S, Vane JR: Pharmacology and endogenous roles of prostaglandin endoperoxides, thromboxane $\mathrm{A}_{2}$ and prostacyclin. Pharmacol Rev 1979;30:293-331.

26. Macdonald PS, Read MA, Dusting GJ: Synergistic inhibition of platelet aggregation by endothelium-derived relaxing factor and prostacyclin. Thromb Res 1988;49:437-449.

27. Feletou M, Vanhoutte PM: Endothelium-dependent hyperpolarization of canine coronary smooth muscle. Br J Pharmacol 1988;93:515-524.

28. Komori K, Lorenz RR, Vanhoutte PM: Nitric oxide, acetylcholine, and electrical and mechanical properties of canine arterial smooth muscle. Am J Physiol 1988;255:H207-212.

29. Tare M, Parkington HC, Coleman HA, et al: Hyperpolarisation and relaxation of arterial smooth muscle caused by nitric oxide derived from the endothelium. Nature 1990;346:69-71.

30. Standen NB, Quayle JM, Davies NW, et al: Hyperpolarising vasodilators activate ATP-sensitive $\mathrm{K}^{+}$channels in arterial smooth muscle. Science 1989;245:177180.

31. Miller VM, Vanhoutte PM: Endothelium-dependent contractions to arachidonic acid are mediated by products of cyclooxygenase in canine veins. Am J Physiol 1985;248:H432-437.

32. Katusic ZS, Vanhoutte PM: Superoxide anion is an endothelium-derived contracting factor. Am J Physiol 1989;257:H33-37.

33. Yanagisawa $M$, Kurihara $H$, Kimura S, et al: A novel potent vasoconstrictor peptide produced by vascular endothelial cells. Nature 1988;332:411-415.

34. Kimura S, Kasuya Y, Sawamura T, et al: Structure-activity relationships of endothelin: importance of the cterminal moiety. Biochem Biophys Res Commun 1988;156:1182-1186.

35. Boulanger C, Lüscher TF: Release of endothelin from 
the porcine aorta: inhibition by endothelium-derived nitric oxide. J Clin Invest 1990;85:587-590.

36. Kasuya $Y$, Ishikawa $T$, Yanagisawa M, et al: Mechanism of contraction to endothelin in isolated porcine coronary artery. Am J Physiol 1989;257:H1828-1835.

37. Kiowski W, Lüscher TF, Linder L, Bühler FR: Endothelin-1-induced vasoconstriction in man: Reversal by calcium channel blockade but not by nitrovasodilators or endothelium-derived relaxing factor. Circulation 1991;83:469-475.

38. Lüscher TF, Yang Z, Tschudi M, et al: Interaction between endothelin-1 and endothelium-derived relaxing factor in human arteries and veins. Circ Res 1990;66:1088-1094.

39. Suzuki N, Matsumoto $\mathrm{H}$, Kitada $\mathrm{C}$, et al: Immunoreactive endothelin- 1 in plasma detected by a sandwichtype enzyme immunoassay. J Cardiovasc Pharmacol 1989;13(suppl 5):151-152.

40. Lüscher TF, Boulanger CM, Dohi Y, Yang Z: Endothelium-derived contracting factors. Hypertension 1992;19:117-130.

41. Yoshimoto S, Ishizaki Y, Mori A, et al: The role of cerebral microvessel endothelium in regulation of cerebral blood flow through production of endothelin-1 (abst). J Vasc Med Biol 1990;2(4):178.

42. Yokokawa K, Kohno M, Yasunari K, et al: Endothelin-3 regulates endothelin-1 production in cultured human endothelial cells. Hypertension 1991;18:304-315.

43. Stewart DJ, Langleben D, Cernacek P, Cianflone K: Endothelin release is inhibited by coculture of endothelial cells with cells of vascular media. Am J Physiol 1990;259:H1928-1932.

44. Boulanger CM, Lüscher TF: Hirudin and nitric oxide donors inhibit the thrombin-induced release of endothelin from the intact porcine aorta. Circ Res 1991;68:1768-1772.

45. Saijonmaa O, Ristimäki A, Fyhrquist F: Atrial natriuretic peptide, nitroglycerine, and nitroprusside reduce basal and stimulated endothelin production from cultured endothelial cells. Biochem Biophys Res Commun 1990;173: 514-520.

46. Clozel M, Fischli W, Guilly C: Specific binding of endothelin on human vascular smooth muscle cells in culture. J Clin Invest 1989;83:1758-1761.

47. Yang Z, von Segesser L, Bauer E, et al: Different mobilization of calcium in endothelin-1-induced contractions in human arteries and veins: effects of calcium antagonists. J Cardiovasc Pharmacol 1990;16:654-660.

48. Goto K, Kasuya Y, Matsuki T, et al: Endothelin activates the dihydropiridine-sensitive, voltage-dependent $\mathrm{Ca}^{2+}$ channel in vascular smooth muscle. Proc Natl Acad Sci USA 1989;86:3915-3918.

49. Dohi Y, Lüscher TF: Endothelin-1 in hypertensive resistance arteries: intraluminal and extraluminal dysfunction. Hypertension 1991;18:543-549.

50. Fukuda $\mathrm{Y}$, Hirata $\mathrm{Y}$, Yoshimi H, et al: Endothelin is a potent secretagogue for atrial natriuretic peptide in cultured rat atrial myocytes. Biochem Biophys Res Commun 1988;155:167-172.

51. Baumgartner HR, Studer A: Gezielte Ueberdehnung der Aorta abdominalis am normo- und hypercholesteraemischen Kaninchen. Pathol Microbiol (Basel) 1963;26:129-148.

52. Hannan RL, Kourembanas S, Flanders KO, et al: Endothelial cells synthesize basic fibroblast growth factor and transforming growth factor beta. Growth Factors 1988;1:7-18.

53. Garg UC, Hassid A: Nitric oxide-generating vasodilators and 8-bromo-cyclic guanosine monophosphate inhibit mitogenesis and proliferation of cultured rat vascular smooth muscle cells. J Clin Invest 1989;83:17741777.

54. DiCorleto PE, Fox PL: Growth factor production by endothelial cells, in Ryan U (ed): Endothelial Cells. Boca Raton, CRC Press, 1990, volume II, pp 51-62.

55. Dubin D, Pratt RE, Cooke JP, Dzau VJ: Endothelin, a potent vasoconstrictor, is a vascular smooth muscle mitogen. J Vasc Med Biol 1989;1:13-17.

56. Ross R: The pathogenesis of atherosclerosisAn update. N Engl J Med 1986;314:488-498.

57. Predel HG, Yang Z, Lüscher TF: Pulsatile stretch stimulates growth of saphenous vein but not mammary artery smooth muscle: Implications for coronary bypass graft disease. Lancet 1992;340:878-879.

58. Koga T, Takata Y, Kobayashi K, et al: Age and hypertension promote endothelium-dependent contractions to acetylcholine in the aorta of the rat. Hypertension 1989;14:542-548.

59. Dohi Y, Lüscher TF: Aging differentially affects direct and indirect actions of endothelin-1 in perfused mesenteric arteries of the rat. Br J Pharmacol 1990;100:889-893.

60. Vita JA, Treasure CB, Nabel EG: Coronary vasomotor response to acetylcholine relates to risk factors for coronary artery disease. Circulation 1990;81:491-497.

61. Shimokawa H, Flavahan NA, Vanhoutte PM: Natural course of the impairment of endothelium-dependent relaxations after balloon endothelium removal in porcine coronary arteries. Circ Res 1989;65:740-753.

62. Ylà-Herttuala S, Palinski W, Rosenfeld ME, et al: Evidence for the presence of oxidatively modified lowdensity lipoproteins in atherosclerotic lesions of rabbit and man. J Clin Invest 1989;84:1086-1095.

63. Tanner FC, Noll G, Boulanger CM, Lüscher TF: Oxidized native low-density lipoproteins inhibit relaxations of porcine coronary arteries: role of scavenger receptor and endothelium-derived nitric oxide. Circulation 1991;83:2012-2021.

64. Kugiyama K, Kerns SA, Morrisett JD, et al: Impairment of endothelium-dependent arterial relaxation by lysolecithin in modified low-density lipoproteins. Nature 1990;344:160-162.

65. Tanner FC, Tschudi MR, Lüscher TF: Endothelium, lipoproteins and atherosclerotic vascular disease. Vasc Med Rev 1991;2:161-176.

66. Shimokawa H, Vanhoutte PM: Impaired endotheliumdependent relaxation to aggregating platelets and related vasoactive substances in porcine coronary arteries in hypercholesterolemia and in atherosclerosis. Circ Res 1989;64:900-914.

67. Drexler H, Zeiher AM, Meinzer K, Just H: Correction of 
endothelial dysfunction in coronary microcirculation of hypercholesterolemic patients by L-arginine. Lancet 1991;338:1546-1550.

68. Galle J, Mülsch A, Busse R, Bassenge E: Effects of native and oxidized low-density lipoproteins on formation and inactivation of endothelium-derived relaxing factor. Arterio Thromb 1991;11:198-203.

69. Simon BC, Cunningham LD, Cohen RA: Oxidized lowdensity lipoproteins cause contraction and inhibit endothelium-dependent relaxation in the pig coronary artery. J Clin Invest 1990;86:75-79.

70. Galle J, Bassenge E, Busse R: Oxidized low-density lipoproteins potentiate vasoconstrictions to various agonists by direct interaction with vascular smooth muscle. Circ Res 1990;66:1287-1293.

71. Boulanger CM, Tanner FC, Béa ML, et al: Oxidized low-density lipoproteins induce mRNA expression and release of endothelin from human and porcine endothelium. Circ Res 1992;70:1191-1197.

72. Yang Z, Richard V, von Segesser L, et al: Threshold concentrations of endothelin-1 potentiate contractions to norepinephrine and serotonin in human arteries: a new mechanism of vasospasm? Circulation 1990;82:188-195.

73. Lüscher TF: Imbalance of endothelium-derived relaxing and contracting factors: a new concept in hypertension? Am J Hypertens 1990;3:317-330.

74. Dohi Y, Thiel MA, Bühler FR, Lüscher TF: Activation of endothelial L-arginine pathway in resistance arteries. Hypertension 1990;16:170-179.

75. Tschudi MR, Criscione L, Lüscher TF: Effect of aging and hypertension on endothelium in rat coronary arteries. J Hypertens 1991;9(suppl 6):164-165.

76. Bossaller C, Habib GB, Yamamoto H, et al: Impaired muscarinic endothelium-dependent relaxation and cyclic guanosine 5'-monophosphate formation in atherosclerotic human coronary artery and rabbit aorta. J Clin Invest 1987;79:170-174.

77. Förstermann U, Mügge A, Alheid U, et al: Selective attenuation of endothelium-mediated vasodilation in atherosclerotic human coronary arteries. Circ Res 1988;62:185-190.

78. Ludmer PL, Selwyn AP, Shook TL, et al: Paradoxical vasoconstriction induced by acetylcholine in atherosclerotic coronary arteries. $\mathrm{N}$ Engl J Med 1086;315:1046-1051.

79. Golino P, Piscione F, Willerson JT, et al: Divergent effects of serotonin on coronary-artery dimensions and blood flow in patients with coronary atherosclerosis and control patients. N Engl J Med 1991;324:641-648.

80. Minor RL, Jr., Myers PR, Guerra R, Jr., et al: Diet-induced atherosclerosis increases the release of nitrogen oxides from rabbit aorta. J Clin Invest 1990;86:21092116.

81. Loop FD, Lytle BW, Cosgrove DM, et al: Influence of the internal mammary artery graft on 10-year survival and other cardiac events. N Engl J Med 1986;314:1-6.

82. Lüscher TF, Diederich D, Siebenmann R, et al: Difference between endothelium-dependent relaxations in arterial and in venous coronary bypass grafts. $\mathrm{N}$ Engl J Med 1988;319:462-467.

83. Yang $Z$, Stulz $P$, von Segesser $L$, et al: Different interactions of platelets with arterial and venous coronary bypass vessels. Lancet 1991;337:939-943.

84. Yang Z, Siebenmann $R$, Studer $M$, et al: Similar endothelium-dependent relaxation, but enhanced contractility of the right gastroepiploic artery as compared with the internal mammary artery. J Thorac Cardiovasc Surg 1992;104:459-464. 